\title{
Lateral-Torsional Buckling Analysis for Doubly Symmetric Tubular Flange Composite Beams with Lateral Bracing under Concentrated Load
}

\author{
Yingchun Liu ${ }^{1}$, Ziwen He ${ }^{1}$, Wenfu Zhang ${ }^{1,2}{ }^{,}$,ing Ji ${ }^{1}$, Yuchen Liu ${ }^{3, *}$, Zizhen Wang ${ }^{3}$, Ruili Wang ${ }^{4, *}$, Kailin Yang ${ }^{1}$ \\ and Zhichao Zhang ${ }^{1}$
}

check for

updates

Citation: Liu, Y.; He, Z.; Zhang, W.; Ji, J.; Liu, Y.; Wang, Z.; Wang, R.; Yang, K.; Zhang, Z. Lateral-Torsional Buckling Analysis for Doubly Symmetric Tubular Flange Composite Beams with Lateral Bracing under Concentrated Load. Symmetry 2021, 13, 2328. https://doi.org/10.3390/ sym 13122328

Academic Editor: Huaping Wang

Received: 29 October 2021

Accepted: 2 December 2021

Published: 5 December 2021

Publisher's Note: MDPI stays neutral with regard to jurisdictional claims in published maps and institutional affiliations.

Copyright: (c) 2021 by the authors. Licensee MDPI, Basel, Switzerland. This article is an open access article distributed under the terms and conditions of the Creative Commons Attribution (CC BY) license (https:// creativecommons.org/licenses/by/ $4.0 /)$.
1 Heilongiang Key Lab of Disaster Prevention, Mitigation and Protection Engineering, Northeast Petroleum University, Daqing 163318, China; lycdqpi@nepu.edu.cn (Y.L.); $18733513103 @ 163 . c o m$ (Z.H.); zhang_wenfu@njit.edu.cn (W.Z.); jijing@nepu.edu.cn (J.J.); yang13614596758@163.com (K.Y.); nepuzzc@163.com (Z.Z.)

2 School of Architecture Engineering, Nanjing Institute of Technology, Nanjing 211167, China

3 Handan Key Laboratory of Building Physical Environment and Regional Building Protection Technology, School of Architecture and Art, Hebei University of Engineering, Handan 056038, China; zizhenwang1@163.com

4 School of Management Engineering and Business, Hebei University of Engineering, Handan 056038, China

* Correspondence: liuyuchen@hebu.edu.cn (Y.L.); yuanguanghua@hebeu.edu.cn (R.W.)

\begin{abstract}
Tubular flange composite beams are increasingly applied in modern bridge structures. In order to investigate the overall stability behavior of doubly symmetric tubular flange composite beams with lateral bracing under concentrated load, the analysis of elastic lateral-torsional buckling is conducted by the energy variation method. The analytical solution of critical moment of doubly symmetric tubular flange composite beams with lateral bracing is obtained. Meanwhile, the simplified calculation formula of critical moment is fitted by 1stOpt software based on 26,000 groups of data, and the accuracy is verified by the finite element method. It is found that, the critical moment rises obviously with increasing lateral bracing stiffness, and adding lateral bracing to doubly symmetric tubular flange composite beams is beneficial to improve the overall stability in engineering practice. Finally, the influence of several parameters including concrete strength, span, steel ratio of flange and height-thickness ratio of web are studied. The results show that the concrete strength and the web height-thickness ratio have a weak influence on critical moment of elastic lateral-torsional buckling, while the influence of span-depth ratio and flange steel ratio is very significant.
\end{abstract}

Keywords: doubly symmetric tubular flange composite beams; lateral bracing; lateral-torsional buckling; critical moment; finite element method

\section{Introduction}

The tubular flange composite beam is a novel composite beam in highway bridges, which replaces flat flange of traditional I-shaped steel beam with concrete-filled steel tubular flange. This type of composite beam is advantageous for overall stability because of its higher strength and greater torsional stiffness [1-3]. In recent years, the flexural behavior and stability of doubly symmetric and monosymmetric tubular flange beams have been concerned by many scholars [4,5]. Kim and Sause et al. [6-8] studied the lateraltorsional buckling performance of tubular flange composite beams by carrying out flexural experiments and finite element analysis. Cho [9] investigated the flexural resistance of monosymmetric tubular flange composite beams by two-point loading tests on seven specimens. Theoretical equations to estimate the flexural strength of new type composite beams were presented, and their accuracy was examined by comparing the predictions of the equations with the test results. Rana [10] researched mechanical properties of monosymmetric tubular flange composite beams under the combined action of bending 
and tensile axial force. Based on the finite element analysis results, the moment-axial force interaction relationship was revealed, and a simplified calculation formula was presented. Yan [11] put forward a simplified formula for calculating the flexural capacity of monosymmetric tubular flange composite beams based on the mechanical properties and failure mechanism. Zhang et al. [12-15] proposed the calculation formulas of elastic and plastic flexural capacity of four kinds of monosymmetric tubular flange composite beams by the experimental and theoretical studies, and the formulas for calculating the critical moment of lateral-torsional buckling were provided based on the plate-beam theory. Wang et al. [16] deduced the simplified calculation formulas of yield moment and ultimate flexural capacity of doubly symmetric and monosymmetric tubular flange composite beams. Gao et al. [17] investigated lateral-torsional buckling behavior of high-strength steel tubular flange composite beams by experimental and numerical methods. The research suggested that the infilled concrete could improve the resistance to flange distortion and the flange depth influenced on the lateral-torsional buckling strength remarkably.

In practical engineering, the steel beams as lateral bracings are connected between the tubular flange composite beams, which can provide lateral constraints and improve stability. Many studies on the stability of steel beams with lateral bracing have been carried out. Taylor [18] and Tong [19] studied the stability performance of doubly symmetric I-shaped simply supported steel beams with lateral bracing and proposed the analytical solution of the critical moment of the elastic lateral-torsional buckling. Wu [20] and Zou [21] discussed the influence of lateral bracing on the overall stability of doubly symmetric Ibeam under different loads. Zhang et al. [22,23] proposed the formulas for calculating the critical moment of elastic lateral-torsional buckling of two-span doubly symmetric steel beams and I-shaped cantilever steel beams with lateral bracing by energy variation method. Based on the plate-beam theory, Deng [24] researched the stability performance of monosymmetric tubular flange composite beams and fitted the calculation formula of the elastic critical moment. At present, there are few studies on the stability of doubly symmetric tubular flange composite beams with lateral bracing.

Based on this background, the elastic stability of doubly symmetric tubular flange composite beams with lateral bracing are carried out and provide the critical moment calculation formula in this paper. Firstly, the total potential energy equation of the elastic lateral-torsional buckling for doubly symmetric tubular flange composite beams with lateral bracing under concentrated load is established by the energy variation method. The dimensionless parameters are introduced to calculate the analytical solution of the critical moment. Furthermore, the critical moment calculation formula of elastic lateral-torsional buckling is fitted through 1stOpt software, and the accuracy of the formula is verified by finite element analysis, which can provide technical support for the subsequent research and application of this type of beam. Finally, the effect of concrete strength, span, steel ratio of flange and height-thickness ratio of web on the elastic lateral-torsional buckling critical moment of doubly symmetric tubular flange composite beams are discussed.

\section{Lateral-Torsional Buckling Equation}

\subsection{Basic Information}

The calculation diagram of doubly symmetric tubular flange composite beams with lateral bracing under concentrated load is shown in Figure 1. Lateral bracing is set at the upper flange of mid-span. Where $P_{\mathrm{y}}$ is the concentrated load acting on the upper flange, $L$ is the span of doubly symmetric tubular flange composite beams, $h$ is the distance between the upper and lower tubular flange centroid, and $k_{\mathrm{L}}$ is the lateral bracing stiffness. 


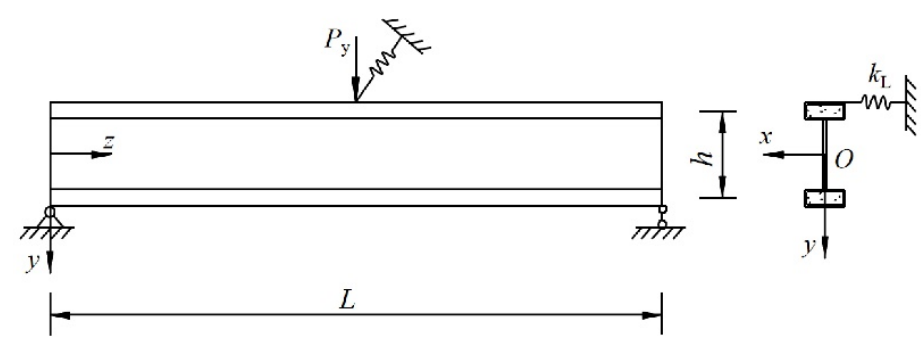

Figure 1. Calculation diagram of doubly symmetric tubular flange composite beams with lateral bracing under concentrated load.

The sectional geometric parameters of doubly symmetric tubular flange composite beams are shown in Figure 2a. The section of tubular flange composite beams is biaxial symmetry, where $H$ is the cross-sectional height, $b_{\mathrm{f}}$ is the width of the tubular flange, $t_{\mathrm{f}}$ is the height of the tubular flange, $t$ is the thickness of the tubular flange, $t_{\mathrm{w}}$ is the thickness of web, and $h_{\mathrm{w}}$ is the height of web.

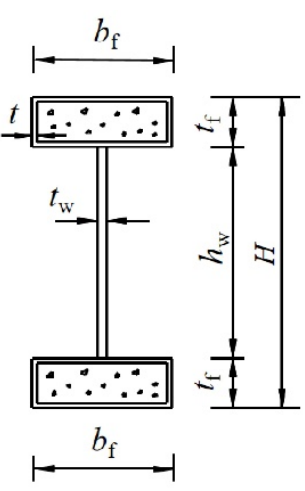

(a)

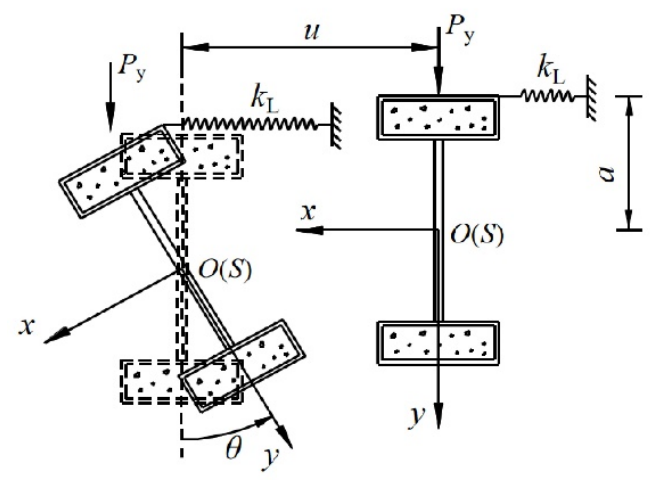

(b)

Figure 2. Section size and lateral-torsional buckling deformation diagram of doubly symmetric tubular flange composite beams: (a) Section size. (b) Lateral-torsional deformation.

The lateral-torsional deformation of doubly symmetric tubular flange composite beams with lateral bracing under concentrated load is shown in Figure $2 \mathrm{~b}$. The section of beam is doubly symmetric, then shear center $S$ and centroid $O$ is coincident. Where $u$ is the lateral displacement of the shear center, $\theta$ is the torsion angle of the section around the shear center, $a$ is the distance from the load point to the shear center.

\subsection{Basic Assumptions}

The following assumptions are adopted for the lateral-torsional buckling of tubular flange composite beams:

1. The deformation shape of the cross section of the beam conforms to rigid peripheral assumption.

2. The torsional deformation of webs can be decomposed into in-plane deformation and out-of-plane deformation, and the corresponding strain energy is determined by Euler beam model and Kirchhoff plate model respectively;

3. The torsional deformation of concrete-filled steel tubular flange can be decomposed into in-plane deformation and out-of-plane deformation, and the corresponding strain energy is determined by the Euler beam mechanical model and Saint-Venant torsional mechanical model separately.

4. The relative slip between steel tube and concrete is not considered, and the deformation between them is coordinated. 


\subsection{Total Potential Energy Equation}

The total potential energy equation of doubly symmetric tubular flange composite beam under concentrated load without lateral bracing can be expressed as [25-27]:

$$
\Pi_{1}=\frac{1}{2} \int_{0}^{L}\left[\left(E I_{\mathrm{y}}\right)_{\mathrm{comp}} u^{\prime \prime 2}+\left(E I_{\omega}\right)_{\mathrm{comp}} \theta^{\prime \prime 2}+\left(G J_{\mathrm{k}}\right)_{\mathrm{comp}} \theta \prime^{2}-2 M_{\mathrm{x}} u^{\prime \prime} \theta\right] d z-\frac{1}{2} \sum P_{i} a_{i} \theta_{i}^{2}
$$

where $\left(E I_{\mathrm{y}}\right)_{\text {comp }}$ is the flexural stiffness around weak axis of composite beam, $\left(G J_{\mathrm{k}}\right)_{\text {comp }}$ is the free torsional stiffness, $\left(E I_{\omega}\right)_{\text {comp }}$ is the restrained torsional stiffness, and $M_{\mathrm{x}}$ is the moment of doubly symmetric tubular flange composite beam under concentrated load.

Due to the complexity of the open and closed cross-section, the existing theory cannot solve this problem accurately. Therefore, according to the plate-beam theory proposed by Zhang [12], the formulas of $\left(E I_{\mathrm{y}}\right)_{\mathrm{comp}},\left(E I_{\omega}\right)_{\mathrm{comp}}$ and $\left(G J_{\mathrm{k}}\right)_{\text {comp }}$ can be expressed as [13]:

$$
\begin{aligned}
& \left(E I_{\mathrm{y}}\right)_{\mathrm{comp}}=\frac{E_{\mathrm{s}}}{1-\mu_{\mathrm{s}}^{2}}\left(\frac{h_{\mathrm{w}} t_{\mathrm{w}}^{3}}{12}\right)+2\left[E_{\mathrm{s}}\left(\frac{t_{\mathrm{f}} b^{3} \mathrm{f}}{12}-\frac{t_{\mathrm{fc}} b^{3} \mathrm{fc}}{12}\right)+E_{\mathrm{c}}\left(\frac{t_{\mathrm{fc}} b^{3} \mathrm{fc}}{12}\right)\right] \\
& \left(E I_{\mathrm{w}}\right)_{\mathrm{comp}}=\frac{E_{\mathrm{s}}}{1-\mu_{\mathrm{s}}^{2}}\left(\frac{h_{\mathrm{w}}^{3} t_{\mathrm{w}}^{3}}{144}\right)+2\left(\frac{h}{2}\right)^{2}\left[E_{\mathrm{s}}\left(\frac{t_{\mathrm{f}} b_{\mathrm{f}}^{3}}{12}-\frac{t_{\mathrm{fc}} b^{3} \mathrm{fc}}{12}\right)+E_{\mathrm{c}} \frac{t_{\mathrm{fc}} b_{\mathrm{fc}}^{3}}{12}\right] \\
& \left(G J_{\mathrm{k}}\right)_{\mathrm{comp}}=G J_{\mathrm{kw}}+2 G J_{\mathrm{kf}} \\
& G J_{\mathrm{kw}}=G_{\mathrm{s}} h_{w} t^{3}{ }_{\mathrm{w}}^{3} \\
& G J_{\mathrm{kf}}=t_{\mathrm{f}}^{4} G_{\mathrm{s}}\left[0.8206 \frac{2 s^{2}}{r^{2}(r+s)}-0.3649 \frac{1}{r^{2}}+\frac{3 r^{4} \mathrm{~s}^{3}+32 r^{2} s^{5}+3 s^{7}}{9 m r^{7}+126 m r^{5} s^{2}+126 m r^{3} s^{4}+9 m r s^{6}}\right]
\end{aligned}
$$

where $G J_{\mathrm{kw}}$ is the free torsional stiffness of web and $G J_{\mathrm{kf}}$ is the free torsional stiffness of tubular flange, $t_{\mathrm{fc}}=t_{\mathrm{f}}-2 t, b_{\mathrm{fc}}=b_{\mathrm{f}}-2 t, r=t_{\mathrm{f}} / t, s=b_{\mathrm{f}} / t, m=G_{\mathrm{s}} / G_{c}, E_{\mathrm{s}}$ is the elastic modulus of steel, $E_{\mathrm{c}}$ is the elastic modulus of concrete, $\mu_{\mathrm{s}}$ is the Poisson's ratio of steel, $G_{\mathrm{s}}$ is the shear modulus of steel, and $G_{c}$ is the shear modulus of concrete.

The total potential energy equation of lateral bracing can be expressed as:

$$
\Pi_{2}=\frac{1}{2} k_{\mathrm{L}}\left[u\left(\frac{L}{2}\right)+a \theta\left(\frac{L}{2}\right)\right]^{2}
$$

\subsection{Displacement Function}

In the case of lateral-torsional deformation of doubly symmetric tubular flange composite beams, the functions of lateral displacement $u(z)$ and rotation angle $\theta(z)$ are chosen in the form of six-term trigonometric series, which can be expressed as:

$$
\begin{gathered}
u(z)=\sum_{i=1}^{6} A_{i} h \sin \left(\frac{i \pi z}{L}\right) \\
\theta(z)=\sum_{i=1}^{6} B_{i} \sin \left(\frac{i \pi z}{L}\right)
\end{gathered}
$$

where $A_{i}$ and $B_{i}$ are undetermined coefficients.

Obviously, the selected lateral displacement $u(z)$ and rotation angle $\theta(z)$ functions should satisfy the geometric boundary conditions of doubly symmetric tubular flange composite beam:

$$
\begin{array}{ll}
u(0)=u(L)=0 ; & u^{\prime \prime}(0)=u^{\prime \prime}(L)=0 \\
\theta(0)=\theta(L)=0 ; & \theta^{\prime \prime}(0)=\theta^{\prime \prime}(L)=0
\end{array}
$$

\subsection{Expression of Moment}

The moment $M_{\mathrm{x}}$ of doubly symmetric tubular flange composite beams with lateral bracing under concentrated load can be expressed as:

$$
\left.\begin{array}{ll}
M_{\mathrm{x}}(z)=\frac{1}{2} P_{\mathrm{y}} z & 0<z \leq \frac{L}{2} \\
M_{\mathrm{x}}(z)=\frac{1}{2} P_{\mathrm{y}}(L-z) & \frac{L}{2}<z \leq L
\end{array}\right\}
$$


By substituting Equations (4)-(7) into Equation (1), the total potential energy without bracing can be expressed as:

$$
\Pi_{1}=\frac{1}{2}\left[\frac{\left(E I_{\mathrm{y}}\right)_{\mathrm{comp}} h^{2} \pi^{4} A_{1}^{2}}{2 L^{3}}+\frac{\left(E I_{\mathrm{w}}\right)_{\mathrm{comp}} \pi^{4} B_{1}^{2}}{2 L^{3}}+\frac{\left(G J_{\mathrm{k}}\right)_{\mathrm{comp}} \pi^{2} B_{1}^{2}}{2 L}+\frac{h P\left(4+\pi^{2}\right)}{8} A_{1} B_{1}-a P B_{1}^{2}\right]
$$

By substituting Equations (4) and (5) into Equation (3), the bracing potential energy can be further expressed as:

$$
\Pi_{2}=\frac{1}{2}\left[a\left(B_{1}-B_{3}+B_{5}\right)+A_{1} H-A_{3} H+A_{5} H\right]^{2} k_{L}
$$

Therefore, the total potential energy of doubly symmetric tubular flange composite beam with lateral bracing under concentrated load can be expressed as:

$$
\begin{aligned}
\Pi=\Pi_{1}+\Pi_{2} & =\frac{1}{2}\left[\frac{\left(E I_{\mathrm{y}}\right)_{\mathrm{comp}} h^{2} \pi^{4} A_{1}^{2}}{2 L^{3}}+\frac{\left(E I_{\mathrm{w}}\right)_{\mathrm{comp}} \pi^{4} B_{1}^{2}}{2 L^{3}}+\frac{\left(G J_{\mathrm{k}}\right)_{\mathrm{comp}} \pi^{2} B_{1}^{2}}{2 L}+\frac{h P_{\mathrm{y}}\left(4+\pi^{2}\right)}{8} A_{1} B_{1}-a P_{\mathrm{y}} B_{1}^{2}\right] \\
& +\frac{1}{2}\left[a\left(B_{1}-B_{3}+B_{5}\right)+A_{1} H-A_{3} H+A_{5} H\right]^{2} k_{L}
\end{aligned}
$$

\subsection{Dimensionless Buckling Equation}

According to the stationary value principle of minimum potential energy [25]:

$$
\begin{aligned}
& \frac{\partial \Pi}{\partial A_{i}}=0 \quad(i=1,2,3,4,5,6) ; \\
& \frac{\partial \Pi}{\partial B_{i}}=0 \quad(i=1,2,3,4,5,6) .
\end{aligned}
$$

The definition of dimensionless parameters is introduced as [13,28,29]:

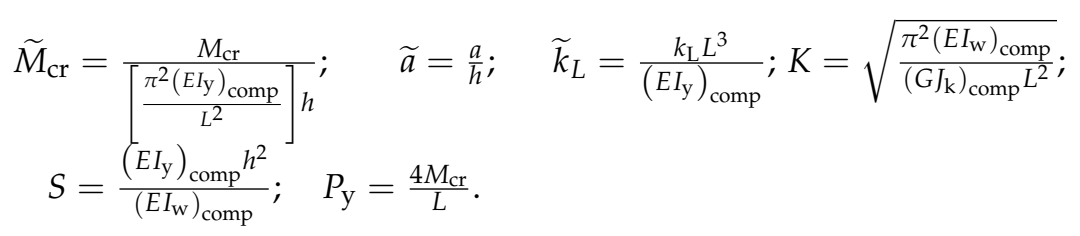

where $M_{\mathrm{cr}}$ is the critical moment of doubly symmetric tubular flange composite beam with lateral bracing under concentrated load; $\widetilde{M}_{\mathrm{cr}}$ is the dimensionless critical moment; $\widetilde{a}$ is the dimensionless position of load; $k_{\mathrm{L}}$ is the lateral bracing stiffness; $\widetilde{k}_{\mathrm{L}}$ is the dimensionless lateral bracing stiffness; $K$ is the torsional stiffness parameter; $S$ is the parameter introduced to characterize the relationship between the bending stiffness around the weak axis and the constrained torsional stiffness.

Multiplying Equation (11) by $L^{3} /\left[\left(E I_{\mathrm{y}}\right)_{\text {comp }} h^{2}\right]$ and substituting dimensionless parameters of Equation (12) into Equation (11), the dimensionless buckling equation can be obtained, which can be expressed in the form of the matrix:

$$
\left[\begin{array}{cc}
{ }^{0} R & { }^{0} S \\
{ }^{0} T & { }^{0} Q
\end{array}\right]\left\{\begin{array}{c}
A \\
B
\end{array}\right\}=\widetilde{M}_{\mathrm{cr}}\left[\begin{array}{cc}
{ }^{1} R & { }^{1} S \\
{ }^{1} T & { }^{1} Q
\end{array}\right]\left\{\begin{array}{c}
A \\
B
\end{array}\right\}
$$

The minimum eigenvalue obtained from Equation (13) is the analytical solution of critical moment of elastic lateral-torsional buckling of doubly symmetric tubular flange composite beam with lateral bracing under concentrated load.

From the above derivation, a series of dimensionless critical moment $\widetilde{M}_{\mathrm{cr}}$ can be obtained by calculating the parameters of $\widetilde{a}, \widetilde{k}_{\mathrm{L}}, S$, and $K$, which are used in the regression of critical moment formula.

\section{Critical Moment Formula}

In this paper, MATLAB software is applied to write a program to calculate the dimensionless critical moment $\widetilde{M}_{\text {cr }}$ of doubly symmetric tubular flange composite beams with lateral bracing under concentrated load, and $\widetilde{M}_{\mathrm{cr}}$ can be calculated by inputting different 
values of $\widetilde{a}, \widetilde{k}_{\mathrm{L}}$, and $K$. Through trial calculation, it is found that when the value of $\widetilde{k}_{\mathrm{L}}$ reaches the dimensionless threshold stiffness $\widetilde{k}_{\mathrm{LT}}$ [30], the dimensionless critical moment $\widetilde{M}_{\mathrm{cr}}$ does not increase any more. Because the threshold stiffness of each beam is different, the change step of dimensionless lateral bracing stiffness $\widetilde{k}_{\mathrm{L}}$ is set as 5 in order to obtain more accurate data. A total 26,000 data of dimensionless critical moment are obtained through calculation for regression of the dimensionless critical moment formula.

Based on the data obtained above, it is found that the dimensionless critical moment of doubly symmetric tubular flange composite beams with lateral bracing continuously increases with the increase of the dimensionless lateral bracing stiffness. When the lateral bracing stiffness reaches the dimensionless threshold stiffness, the critical moment does not increase any more, and its relationship curve is shown in Figure 3.

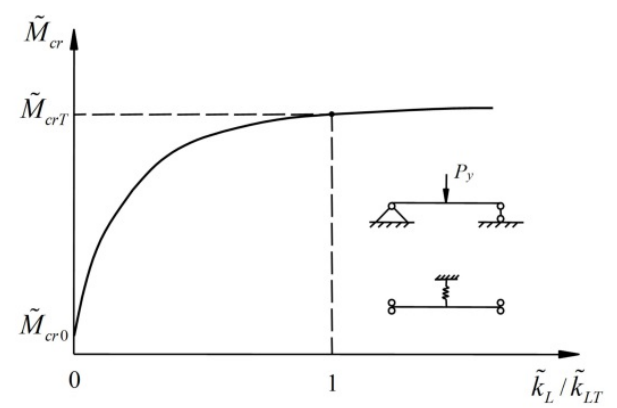

Figure 3. Relationship between dimensionless critical moment and dimensionless torsional stiffness.

The nonlinear regression of dimensionless critical moment is carried out by using 1stOpt software [31,32], and the calculation formula of dimensionless critical moment of doubly symmetric tubular flange composite beams with lateral bracing under concentrated load is fitted:

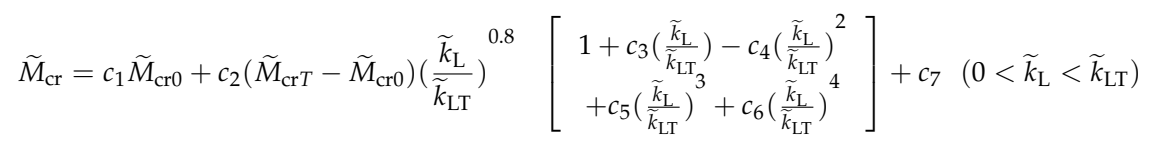

where $c_{1}, c_{2}, c_{3}, c_{4}, c_{5}, c_{6}$ and $c_{7}$ are coefficients and the values of coefficients are shown in Table 1. $\widetilde{M}_{\mathrm{cr} 0}$ is the calculation formula of elastic lateral-torsional buckling of doubly symmetric tubular flange composite beams under concentrated load without lateral bracing, which can be expressed as [33]:

$$
\widetilde{M}_{\mathrm{cr} 0}=\beta_{1}\left[\beta_{2} \widetilde{a}+\beta_{3} K^{-1}+\sqrt{\left(\beta_{2} \widetilde{a}\right)^{2}+S\left(1+K^{-2}\right)+\beta_{4} K^{-1}}\right]
$$

where $\beta_{1}, \beta_{2}, \beta_{3}$ and $\beta_{4}$ are coefficients and the values are shown in Table 2 .

Table 1. The values of parameters of Equation (14).

\begin{tabular}{cccccccc}
\hline Parameter & $c_{1}$ & $c_{2}$ & $c_{3}$ & $c_{4}$ & $c_{5}$ & $c_{6}$ & $c_{7}$ \\
\hline Value & 0.995 & 1.060 & 0.705 & 1.994 & 1.983 & -0.735 & -0.080 \\
\hline
\end{tabular}

Table 2. The values of parameters of Equation (15).

\begin{tabular}{ccccc}
\hline Parameter & $\beta_{1}$ & $\beta_{2}$ & $\beta_{3}$ & $\beta_{4}$ \\
\hline Value & 0.213 & -4.086 & 1.153 & 1.127 \\
\hline
\end{tabular}

$\widetilde{M}_{\text {crT }}$ is the dimensionless critical moment when $\widetilde{k}_{\mathrm{L}}$ reaches the dimensionless threshold stiffness $\widetilde{k}_{\mathrm{LT}}$, which can be expressed as:

$$
\widetilde{M}_{\mathrm{crT}}=\beta_{1 \mathrm{~T}}\left[\beta_{2 \mathrm{~T}} \widetilde{a}+\beta_{3 \mathrm{~T}} K^{-1}+\beta_{4 \mathrm{~T}} \widetilde{k}_{\mathrm{LT}^{\frac{1}{4}}}+\sqrt{\left(\beta_{2 \mathrm{~T}} \widetilde{a}\right)^{2}+S\left(1+K^{-2}\right)+\beta_{5 \mathrm{~T}} K^{-1}}\right]
$$


where the value of $\beta_{1 \mathrm{~T}}, \beta_{2 \mathrm{~T}}, \beta_{3 \mathrm{~T}}, \beta_{4 \mathrm{~T}}$, and $\beta_{5 \mathrm{~T}}$ are shown in Table 3 and the calculation formula of the dimensionless threshold stiffness $\widetilde{k}_{\mathrm{LT}}$ is:

$$
\widetilde{k}_{L T}=\frac{16 \pi^{3}\left(8+\alpha_{1}\right)\left(4+\alpha_{2}\right)^{1.5}}{1.75\left[\pi \alpha_{3}\left(8+\alpha_{4}\right) \sqrt{4+\alpha_{5}}+32\right]}
$$

where $\alpha_{1}=\gamma_{1} K^{-2}, \alpha_{2}=\gamma_{2} K^{-2}, \alpha_{3}=\gamma_{3} K^{-2}, \alpha_{4}=\gamma_{4} K^{-2}, \alpha_{5}=\gamma_{5} K^{-2}$. The value of the coefficient $\gamma_{1}, \gamma_{2}, \gamma_{3}, \gamma_{4}$ and $\gamma_{5}$ are shown in Table 4 .

Table 3. The values of parameters of Equation (16).

\begin{tabular}{cccccc}
\hline Parameter & $\beta_{1 \mathrm{~T}}$ & $\beta_{2 \mathrm{~T}}$ & $\beta_{3 \mathrm{~T}}$ & $\beta_{4 \mathrm{~T}}$ & $\beta_{5 \mathrm{~T}}$ \\
\hline Value & 0.073 & -26.073 & 17.619 & 8.096 & -41.472 \\
\hline
\end{tabular}

Table 4. The values of parameters of Equation (17).

\begin{tabular}{cccccc}
\hline Parameter & $\gamma_{1}$ & $\gamma_{2}$ & $\gamma_{3}$ & $\gamma_{4}$ & $\gamma_{5}$ \\
\hline Value & -0.218 & 1.701 & 2.014 & -0.218 & 1.285 \\
\hline
\end{tabular}

\section{Finite Element Verification}

In order to verify the correctness of the above theoretical analysis formula, the elastic lateral-torsional buckling analysis of the doubly symmetric tubular flange composite beams with lateral bracing is carried out by ANSYS finite element software. The finite element solutions of critical moment for the doubly symmetric tubular flange composite beams with lateral bracing under concentrated load are obtained.

\subsection{Establishment of Finite Element Model}

The section of tubular flange composite beam is composed of concrete-filled steel tubes and steel web. The materials include two types: steel and concrete. SHELL181 element is used to simulate steel tubes and web of the beam. SOLID65 solid element is used to simulate concrete in steel tube. CONTA173 element is selected as the contact element, which is covered on the concrete solid element and the value of KEYOPT (12) option is set to five, so as to realize the binding contact with the target surface and ensure that the outer normal of the contact surface points to the target surface. TARGE170 element is selected as the target element, which is used to describe the target surface related to the contact element. In the model, the target surface is the inner surface of the steel tube [34]. In order to acquire adequate accuracy, different mesh sizes are considered. The steel tube flanges and web are divided into thirty parts along the span, the steel tube along the width is divided into four parts, the steel tube along the height is divided into two parts, and the meshing of internal concrete is coincident with steel tube flange, so that contact pairs can be established at their interface. The web along the height is divided into eight parts.

COMBIN14 spring element is used to simulate the elastic lateral bracing and the lateral bracing stiffness is defined by real constants. The finite element model (FEM) is established, as shown in Figure 4. In order to satisfy the assumption of rigid perimeter, CERIG command is used to establish constraint equations around the $z$ axis to ensure all nodes of the section have the same rotation degree of freedom. The distribution of rigid perimeter along the beam length is shown in Figure 5. 


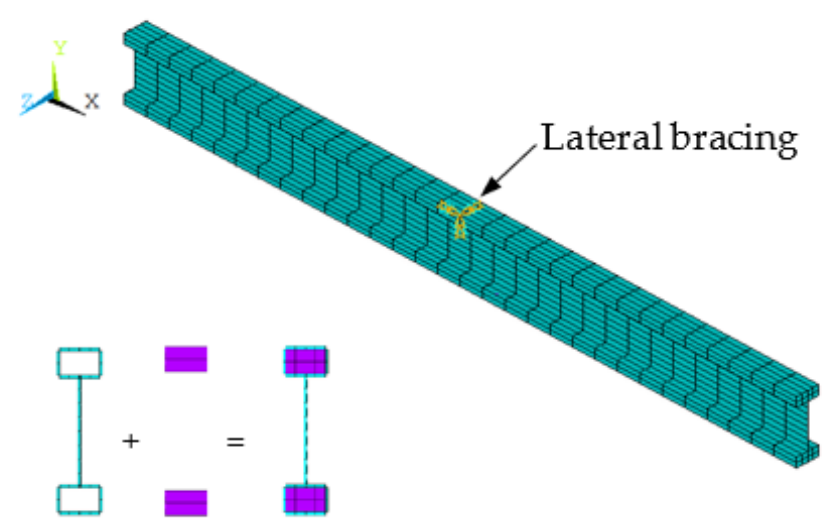

Figure 4. FEM of doubly symmetric tubular flange composite beam with lateral bracing.

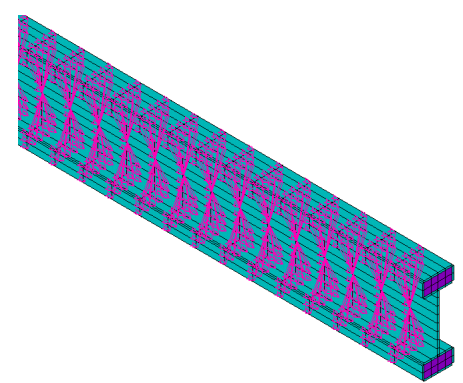

(a)

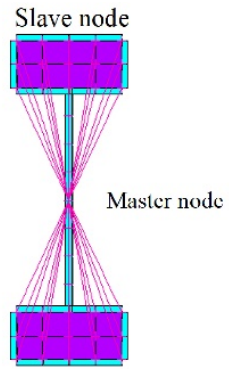

(b)

Figure 5. Rigid perimeter distributed along the beam: (a) Rigid region. (b) Master and slave node.

In order to satisfy the boundary conditions of ideal clamping, the rigid peripheral region in left and right end supports are established by using the constraint equation. The master node is the centroid of the end section. The master nodes are restrained against inplane vertical deflection $(u y)$, out-of-plane horizontal deflection $(u x)$, and twisting rotation (rotz). And the master node of the left end is only restrained against longitudinal horizontal displacement $(u z)$. The left and right boundary conditions are shown in Figure 6.

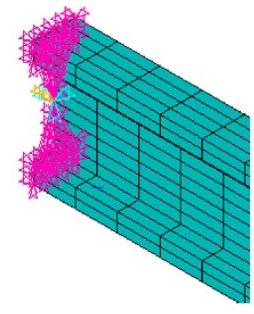

(a)

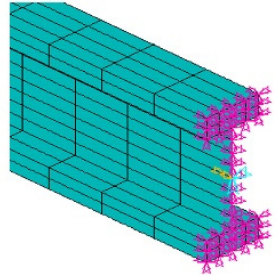

(b)

Figure 6. Boundary conditions: (a) Left end support. (b) Right end support.

\subsection{Verification of Results}

Two doubly symmetric tubular flange composite beams (DSTFCB-1 and DSTFCB-2) of different dimensions are selected for comparative verification, and the geometric dimensions are shown in Table 5.

Table 5. Geometrical dimensions.

\begin{tabular}{cccccccc}
\hline Parameter & $\boldsymbol{L}(\mathbf{m m})$ & $\boldsymbol{H}(\mathbf{m m})$ & $\boldsymbol{b}_{\mathbf{f}}(\mathbf{m m})$ & $\boldsymbol{T}_{\mathrm{f}}(\mathbf{m m})$ & $\boldsymbol{T}(\mathbf{m m})$ & $\boldsymbol{h}_{\mathbf{w}}(\mathbf{m m})$ & $\boldsymbol{t}_{\mathrm{w}}(\mathbf{m m})$ \\
\hline DSTFCB-1 & 3300 & 330 & 60 & 30 & 4 & 270 & 6 \\
DSTFCB-2 & 13,800 & 690 & 180 & 100 & 12 & 490 & 14 \\
\hline
\end{tabular}


The dimensionless threshold stiffness values of DSTFCB-1 and DSTFCB-2 are 1,158,028 and 895,768 respectively. The elastic modulus of steel $E_{\mathrm{S}}$ is $2.06 \times 10^{5} \mathrm{MPa}$, and Poisson's ratio $\mu_{\mathrm{s}}$ is 0.3 . The strength grade of concrete is C40, and elastic modulus of concrete $E_{\mathrm{c}}$ is $3.25 \times 10^{4} \mathrm{MPa}$. The eigenvalue buckling analysis is conducted by ANSYS, and the critical moments are obtained, which are compared with the critical moments of the theoretical Equation (14). The comparison results are shown in Table 6 and Figure 7, the buckling modes of doubly symmetric tubular flange composite beams with lateral bracing are shown in Figure 8.

From Table 6 and Figure 7, it is clear that the results calculated by theoretical Equation (14) are close to those obtained by finite element analysis, with the errors less than $5 \%$. This indicates that the accuracy is very high. Moreover, the critical moment increases with the increase of lateral bracing stiffness. When the lateral bracing stiffness exceeds the threshold stiffness, the critical moment hardly increases. From Figure 8, when lateral bracing stiffness is less than the threshold stiffness, its buckling mode is similar to a sinusoidal half wave, which is symmetric buckling. When the bracing stiffness is greater than the threshold stiffness, the buckling mode is two half waves, which is antisymmetric buckling. It is present that lateral bracing stiffness influences the buckling mode of doubly symmetric tubular flange composite beams.

Table 6. Comparison of critical moments of doubly symmetric tubular flange composite beams with lateral bracing.

\begin{tabular}{|c|c|c|c|c|c|c|c|}
\hline \multicolumn{4}{|c|}{ DSTFCB-1 } & \multicolumn{4}{|c|}{ DSTFCB-2 } \\
\hline$\widetilde{k}_{\mathrm{L}}$ & $\begin{array}{c}M_{\mathrm{cr}}(\mathrm{FEM}) \\
(\mathbf{k N} \cdot \mathbf{m})\end{array}$ & $\begin{array}{c}M_{\mathrm{cr}}(\text { Equation }(14)) \\
(\mathrm{kN} \cdot \mathrm{m})\end{array}$ & $\begin{array}{l}\text { Relative } \\
\text { Error (\%) }\end{array}$ & $\widetilde{k}_{\mathrm{L}}$ & $\begin{array}{c}M_{\mathrm{cr}}(\mathrm{FEM}) \\
\quad(\mathrm{kN} \cdot \mathrm{m})\end{array}$ & $\begin{array}{c}M_{\mathrm{cr}}(\text { Equation }(14)) \\
(\mathrm{kN} \cdot \mathrm{m})\end{array}$ & $\begin{array}{l}\text { Relative } \\
\text { Error (\%) }\end{array}$ \\
\hline 0 & 90 & 89 & 1.11 & 0 & 2018 & 2113 & -4.71 \\
\hline 20 & 116 & 113 & 2.59 & 20 & 2455 & 2578 & -5.01 \\
\hline 40 & 138 & 135 & 2.17 & 40 & 2854 & 2970 & -4.06 \\
\hline 60 & 157 & 154 & 1.91 & 60 & 3197 & 3319 & -3.82 \\
\hline 80 & 174 & 172 & 1.15 & 80 & 3499 & 3631 & -3.77 \\
\hline 100 & 189 & 188 & 0.53 & 100 & 3767 & 3912 & -3.85 \\
\hline 120 & 203 & 202 & 0.49 & 120 & 4009 & 4167 & -3.94 \\
\hline 140 & 214 & 215 & -0.47 & 140 & 4226 & 4402 & -4.16 \\
\hline 160 & 226 & 228 & -0.88 & 160 & 4424 & 4620 & -4.43 \\
\hline 180 & 236 & 239 & -1.27 & 180 & 4604 & 4822 & -4.74 \\
\hline 200 & 245 & 250 & -2.04 & 200 & 4768 & 5002 & -4.91 \\
\hline 220 & 254 & 260 & -2.36 & 220 & 4918 & 5101 & -3.72 \\
\hline 240 & 261 & 266 & -1.92 & 240 & 5056 & 5119 & -1.25 \\
\hline 260 & 263 & 268 & -1.90 & 260 & 5102 & 5136 & -0.67 \\
\hline 280 & 266 & 269 & -1.13 & 280 & 5121 & 5152 & -0.61 \\
\hline 300 & 267 & 271 & -1.50 & 300 & 5147 & 5167 & -0.39 \\
\hline
\end{tabular}

Note. The error is calculated by the formula $\left(M_{\mathrm{cr}(\mathrm{FEM})}-M_{\mathrm{cr}(\mathrm{Equation}(14))}\right) \times 100 \% / M_{\mathrm{cr}(\mathrm{FEM})}$.

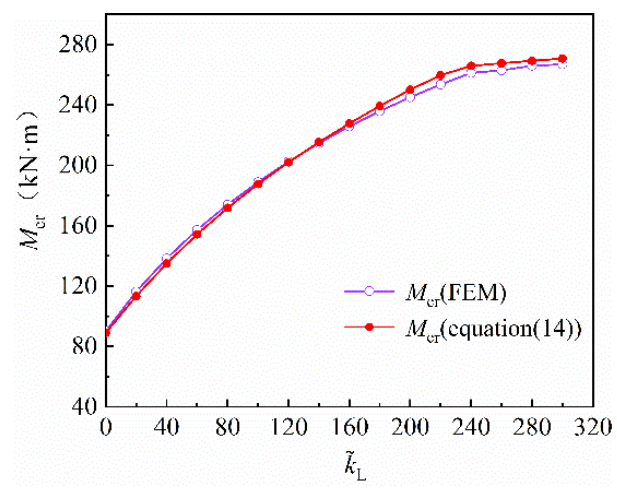

(a)

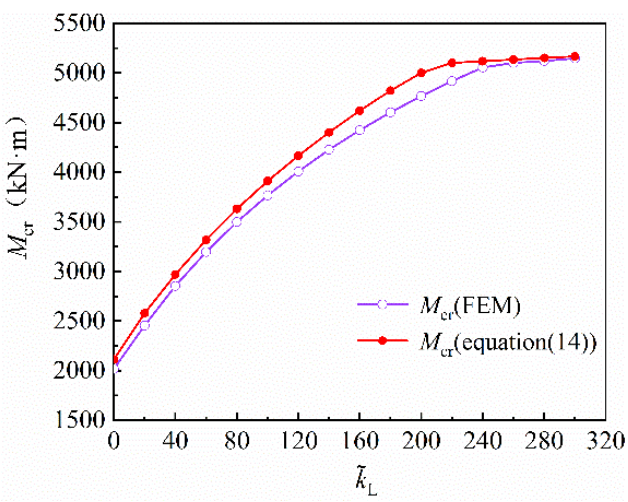

(b)

Figure 7. Critical moment comparison of doubly symmetric tubular flange composite beams with lateral bracing: (a) DSTFCB-1; (b) DSTFCB-2. 


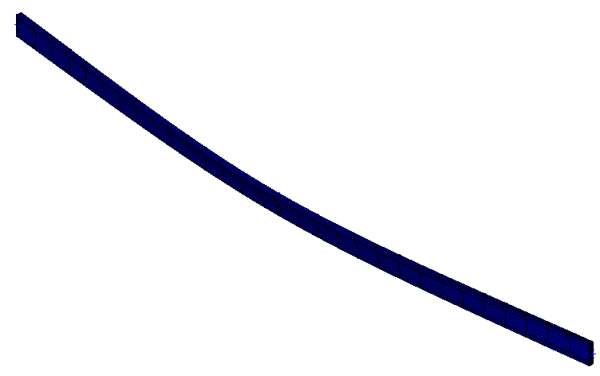

(a)

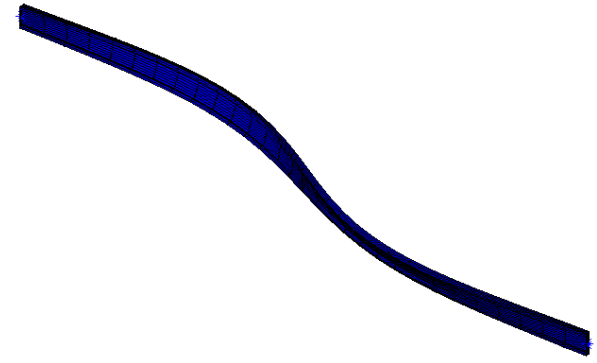

(b)

Figure 8. Buckling modes of doubly symmetric tubular flange composite beams with lateral bracing: (a) $\widetilde{k}_{\mathrm{L}}<\widetilde{k}_{\mathrm{LT}} \cdot(\mathbf{b}) \widetilde{k}_{\mathrm{L}} \geq \widetilde{k}_{\mathrm{LT}}$.

\section{Parameter Analysis}

In order to further understand the factors affecting elastic lateral-torsional buckling critical moment of doubly symmetric tubular flange composite beams with lateral bracing, the parameters such as concrete strength, span, steel ratio of flange and height-thickness ratio of web are analyzed to obtain the influence law on the critical moment.

\subsection{Effect of Concrete Strength}

The yield strength of steel for doubly symmetric tubular flange composite beam is $345 \mathrm{MPa}$, the elastic modulus $E_{\mathrm{s}}$ is $2.06 \times 10^{5} \mathrm{MPa}$, the Poisson's ratio $\mu_{\mathrm{s}}$ is 0.3 , and the concrete strength grades are $\mathrm{C} 40, \mathrm{C} 50$, and C60, respectively $[35,36]$. The calculation results of elastic lateral-torsional buckling critical moment of doubly symmetric tubular flange composite beams are shown in Figure 9.

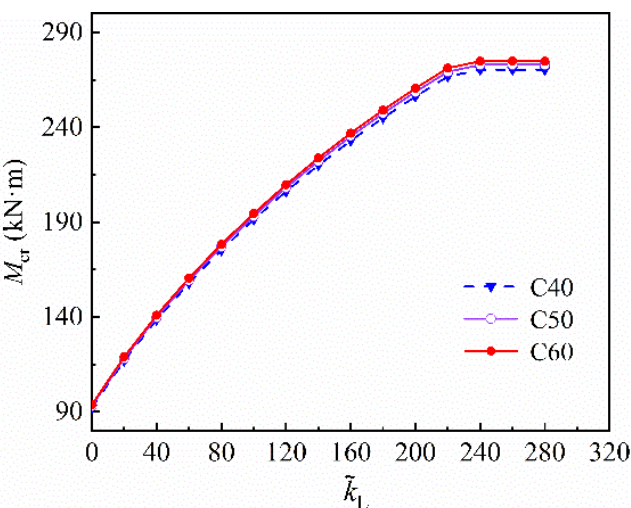

(a)

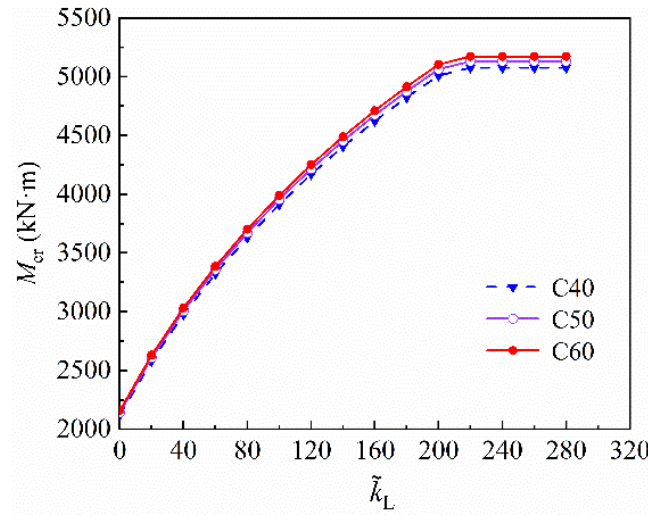

(b)

Figure 9. Effect of concrete strength on critical moments. (a) DSTFCB-1; (b) DSTFCB-2.

From Figure 9, it is clear that the elastic lateral-torsional buckling critical moment of doubly symmetric tubular flange composite beams increases marginally with the increase of concrete strength. The elastic modulus of $\mathrm{C} 40, \mathrm{C} 50$, and $\mathrm{C} 60$ concrete are $3.25 \times 10^{4} \mathrm{MPa}$, $3.45 \times 10^{4} \mathrm{MPa}$, and $3.60 \times 10^{4} \mathrm{MPa}$, respectively. Since the elastic lateral-torsional analysis of beam is carried out in this paper, the impact of concrete on beam is mainly reflected in the change of its elastic modulus. When the concrete strength grade increases from C40 to $\mathrm{C} 60$, the change of elastic modulus is very small, so the change of concrete strength grade has little effect on the critical moment.

\subsection{Effect of Span}

The effect of span-depth ratio on elastic lateral-torsional buckling critical moment of doubly symmetric tubular flange composite beams is studied. The span-depth ratios are shown in Table 7. The yield strength of steel is $345 \mathrm{MPa}$ and the concrete strength grade is C40. The calculation results of critical moment are shown in Figure 10. 
Table 7. Span-depth ratios of DSTFCB-1 and DSTFCB-2.

\begin{tabular}{ccccccccc}
\hline Parameter & \multicolumn{4}{c}{ DSTFCB-1 } & \multicolumn{5}{c}{ DSTFCB-2 } \\
\hline Span $L(\mathrm{~m})$ & 3.3 & 4.95 & 6.6 & 8.25 & 6.9 & 10.35 & 13.8 & 17.25 \\
span-depth ratio $(L / H)$ & 10 & 15 & 20 & 25 & 10 & 15 & 20 & 25 \\
\hline
\end{tabular}

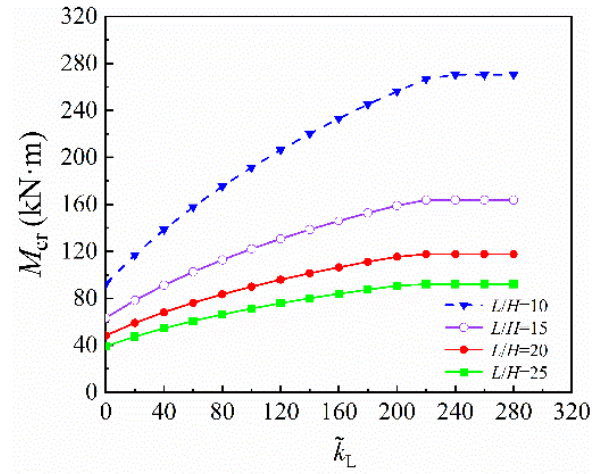

(a)

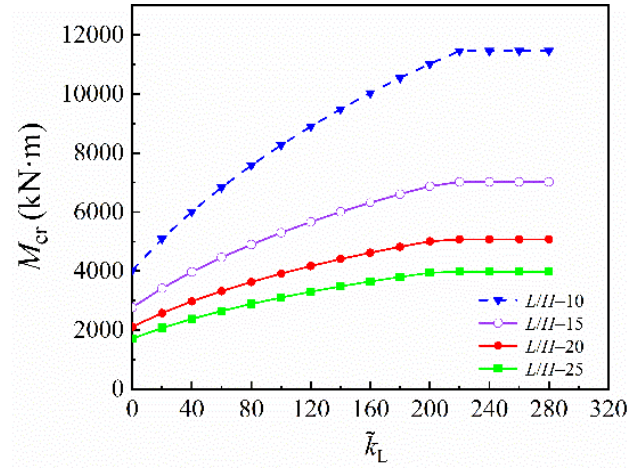

(b)

Figure 10. Effect of span-depth ratio on critical moments. (a) DSTFCB-1; (b) DSTFCB-2.

From Figure 10, it is clear that the critical moment decreases substantially with the increase of span-depth ratio. When the span-depth ratio increases from 10 to 25 , the critical moment decreases range from $34.8 \%$ to $68.8 \%$. It indicates that the effect of span-depth ratio on critical moment is significant.

\subsection{Effect of Steel Ratio of Flange}

The steel ratio of flange can be adjusted by changing the thickness of the steel tube (denoted by symbol $\alpha$ here, $\alpha$ is $A_{\mathrm{fs}} / A_{\mathrm{fc}}$ ), and the values are shown in Table 8 . In the analysis, the yield strength of steel is $345 \mathrm{MPa}$ and the strength grade of concrete is $\mathrm{C} 40$, and other parameters are unchanged. The calculation results of critical moment are shown in Figure 11.

Table 8. Steel ratios of flange of DSTFCB-1 and DSTFCB-2.

\begin{tabular}{ccccccc}
\hline Parameter & \multicolumn{3}{c}{ DSTFCB-1 } & \multicolumn{3}{c}{ DSTFCB-2 } \\
\hline Steel tube thickness $(\mathrm{mm})$ & 2 & 3 & 4 & 8 & 10 & 12 \\
Steel content $\alpha(\%)$ & 23.6 & 38.9 & 57.3 & 30.7 & 40.6 & 51.8 \\
\hline
\end{tabular}

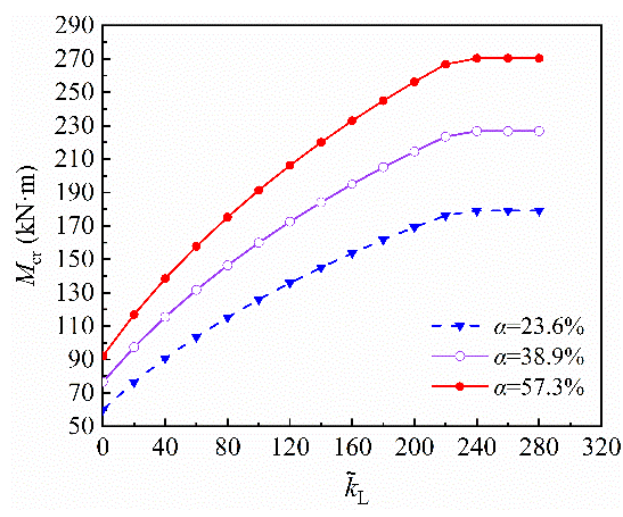

(a)

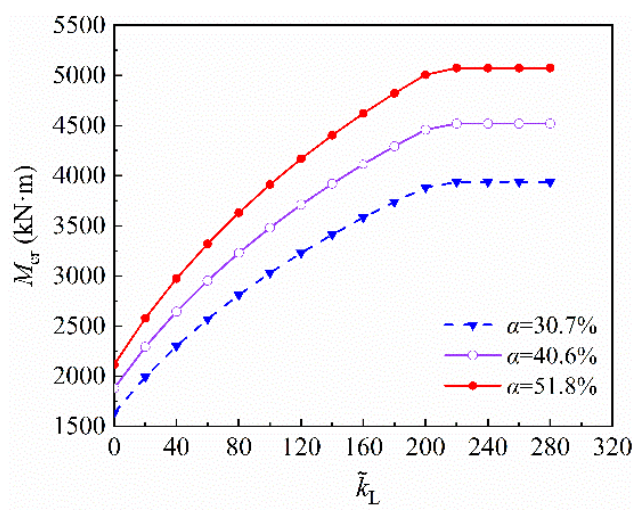

(b)

Figure 11. Effect of steel ratio of flange on critical moments. (a) DSTFCB-1; (b) DSTFCB-2.

From Figure 11, it is clear that the critical moment increases significantly with the increase of steel ratio of flange. When the steel ratio of flange increases from $23.6 \%$ to $57.3 \%$, 
the critical moment increases range from $14.8 \%$ to $53.4 \%$. It indicates that the effect of steel ratio of flange on critical moment is remarkable.

\subsection{Effect of Height-Thickness Ratio of Web}

By changing the thickness of web to adjust the height-thickness ratio of web, the values are shown in Table 9. The yield strength of steel is $345 \mathrm{MPa}$, the strength grade of concrete is C40, and other parameters are unchanged. The calculation results of critical moment are shown in Figure 12.

Table 9. Height-thickness ratios of web of DSTFCB-1 and DSTFCB-2.

\begin{tabular}{ccccccc}
\hline Parameter & \multicolumn{3}{c}{ DSTFCB-1 } & \multicolumn{3}{c}{ DSTFCB-2 } \\
\hline Thickness of web $(\mathrm{mm})$ & 4 & 6 & 8 & 8 & 14 & 18 \\
Height-thickness ratio & 67.5 & 45 & 33.75 & 61.25 & 35 & 27.2 \\
\hline
\end{tabular}

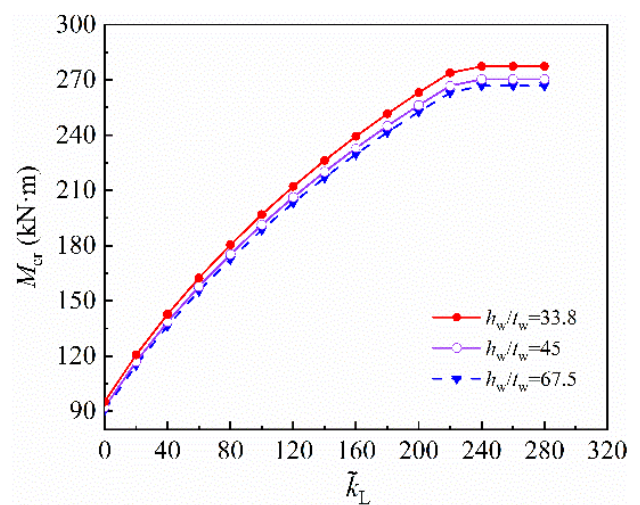

(a)

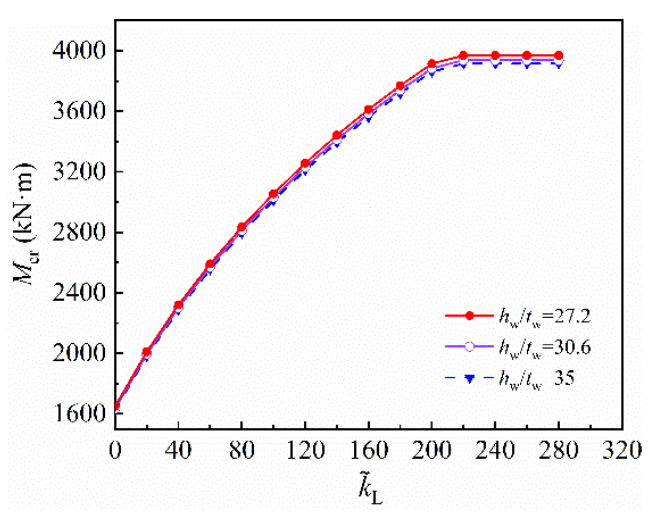

(b)

Figure 12. Effect of height-thickness ratio of web on critical moments. (a) DSTFCB-1; (b) DSTFCB-2.

From Figure 12, it is clear that the critical moment increases slightly with the decrease of the height-thickness ratio of web. When the height-thickness ratio of web increases from $27.2 \%$ to $67.5 \%$, the critical moment decreases range from $1.3 \%$ to $5.1 \%$. This indicates that the effect of height-thickness ratio of web on critical moment is weak.

\section{Conclusions}

This paper focuses on the elastic lateral-torsional buckling for doubly symmetric tubular flange composite beams with lateral bracing under concentrated load. Theoretical and numerical simulation studies are carried out and the following conclusions are obtained:

(1) By establishing the total potential energy equation and introducing dimensionless parameters, the analytical solution of the critical moment of doubly symmetric tubular flange composite beams with lateral bracing under concentrated load is obtained.

(2) Considering the multiple parameters, the dimensionless critical moment calculation formula of doubly symmetric tubular flange composite beams with lateral bracing is fitted by 1 stOpt software, and the accuracy is verified by finite element analysis. This provides a simple method for predicting and analyzing stability behavior of doubly symmetric tubular flange composite beams with lateral bracing.

(3) The calculation formula of dimensionless threshold stiffness $\widetilde{k}_{\mathrm{LT}}$ is given in this paper. When $\widetilde{k}_{\mathrm{L}}<\widetilde{k}_{\mathrm{LT}}$, the critical moment rises noticeably with increasing lateral bracing stiffness. When the lateral bracing stiffness reaches the threshold stiffness, the critical moment tends to be stable, and it is $63 \%$ higher than the critical moment of tubular flange composite beams without lateral bracing. It proves that lateral bracing is beneficial to the overall stability of doubly symmetric tubular flange composite beams.

(4) The increase in concrete strength and web height-thickness ratio has a weaker effect on the critical moment. However, span-depth ratio and flange steel ratio exhibit the 
significant effect on the critical moment. The results can provide a reference for improving the stability of doubly symmetric tubular flange composite beams with lateral bracing.

Author Contributions: Conceptualization, Y.L. (Yingchun Liu); Formal analysis, W.Z.; Methodology, Y.L. (Yingchun Liu) and W.Z.; Software, Z.H., Y.L. (Yuchen Liu), Z.W. and R.W.; Validation, J.J. and Y.L. (Yuchen Liu); Writing—original draft, Y.L. (Yingchun Liu) and Z.H.; Writing—review \& editing, J.J., R.W., K.Y. and Z.Z. All authors have read and agreed to the published version of the manuscript.

Funding: The authors are grateful for the financial support received from the National Natural Science Foundation of China (52178143 and 51578120); The Natural Science Foundation of Heilongjiang Province, grant number LH2020E018; 2021 Social Science Development Research Project of Hebei Province grant number 20210301135; Humanities and Social Science Research Project of Higher Education institutions of Hebei Province, grant number SQ2021115; The Northeast Petroleum University Guided Innovation Fund, grant number 2020YDL-02.

Institutional Review Board Statement: Not applicable.

Informed Consent Statement: Not applicable.

Data Availability Statement: The data used to support the findings of this study are available from the corresponding author upon request.

Conflicts of Interest: The authors declare no conflict of interest.

\section{References}

1. Smith, A. Design of HPS Bridge Birders with Tubular Flanges. Master's Thesis, Lehigh University, Bethlehem, PA, USA, 2001.

2. Malikan, M.; Krasheninnikov, M.; Eremeyev, V.A. Torsional stability capacity of a nano-composite shell based on a nonlocal strain gradient shell model under a three-dimensional magnetic field. Int. J. Eng. Sci. 2020, 148, 103210. [CrossRef]

3. Malikan, M.; Eremeyev, V.A.; Żur, K.K. Effect of Axial Porosities on Flexomagnetic Response of In-Plane Compressed Piezomagnetic Nanobeams. Symmetry 2020, 12, 1935. [CrossRef]

4. Anapayan, T.; Mahendran, M. Numerical Modelling and Design of Litesteel Beams Subject to Lateral Buckling. J. Constr. Steel. Res. 2012, 70, 51-64. [CrossRef]

5. Anapayan, T.; Mahendran, M. Improving the moment capacities of hollow flange cold-formed Litesteel Beams using web stiffeners. In Proceedings of the Rehabilitation and Restoration of Structures: Proceedings of an International Conference held at the Indian Institute of Technology Madras, Chennai, India, 13-16 February 2013; pp. 423-434.

6. Kim, B.G.; Sause, R. High performance steel girders with tubular flanges. Int. J. Steel. Struct. 2005, 5, $253-263$.

7. Sause, R.; Kim, B.G.; Wimer, M.R. Experimental study of tubular flange girders. J. Struct. Eng. 2008, 134, 384-392. [CrossRef]

8. Sause, R. Innovative steel bridge girders with tubular flanges. Struct. Infrastruct. E 2015, 11, 450-465. [CrossRef]

9. Cho, B.H.; Lee, J.S.; Kim, Y.H.; Kim, D.J.; Hsieh, W.H. Flexural Capacity of a New Composite Beam with Concrete-Infilled Tubular Lower Flange. Appl. Sci. 2017, 7, 57. [CrossRef]

10. Rana, A.D.; Katherine, C.A. Design and analysis of concrete-filled tubular flange girders under combined loading. Adv. Struct. Eng. 2021, 24, 2512-2528.

11. Yan, X.J. Experimental Investigation of Bending Behavior for Steel and High Performance Concrete Composite Girders with Concrete Filled Rectangular Up-Flanges. Master's Thesis, Chang'an University, Xi'an, China, 2009.

12. Ren, Y.W. Experimental and Theoretical Investigation of Bending Behavior for Rectangular Steel Tubular Flanges Beams. Master's Thesis, Northeast Petroleum University, Daqing, China, 2015.

13. Liang, W.F. Experimental Research on Global Stability Behavior of I-Beams with Top Flange of Rectangular Concrete-Filled Steel Tube. Master's Thesis, Northeast Petroleum University, Daqing, China, 2016.

14. Zhang, W.F. Out-of-Plane Stability Theory of Steel Structures, 1st ed.; Wuhan University of Technology Press: Wuhan, China, 2018.

15. Chen, K.S. Theoretical Research on Combined Torsion and Flexural-Torsional Buckling of the I-Shaped Beams with Concrete-Filled Steel Tubular Flange Based on the Plate-Beam Theory. Master's Thesis, Northeast Petroleum University, Daqing, China, 2017.

16. Wang, C.S.; Zhu, J.W.; Zhai, X.L.; Wang, X.P.; Liu, H. Flexural behavior experiment of steel and concrete composite girder with double tubular flanges. China J. Highw. Transp. 2017, 30, 147-158.

17. Gao, F.; Yang, F.; Zhu, H.P.; Liang, H.J. Lateral-torsional Buckling Behavior of Concrete-filled High-strength Steel Tubular Flange Beams under Mid-span Load. J. Constr. Steel. Res. 2021, 176, 1-15. [CrossRef]

18. Taylor, A.C.; Ojalvo, M. Torsional restraint of lateral buckling. J. Struct. Div-ASCE 1966, 92, 115-129. [CrossRef]

19. Tong, G.S.; Cheng, S.F. Buckling of laterally and torsional braced beams. J. Constr. Steel. Res. 1988, 11, 41-55.

20. Wu, Y.J. The Effect to Stability of Steel Members by Bracing Location. Master's Thesis, Hehai University, Nanjing, China, 2005.

21. Zou, H.Z. Research on the Influence of Lateral Supporting Conditions on the Overall Stability Carrying Capacity of Steel Beams. Master's Thesis, Hunan University, Changsha, China, 2011. 
22. Zhang, W.F.; Sui, H.Y.; Wang, Z. Buckling Analysis of Two-Span Continuous Beams with Lateral Elastic Brace under Uniform Load. Adv. Mat. Res. 2011, 1067, 641-645. [CrossRef]

23. Zhang, W.F.; Liu, Y.C.; Hou, G.L. Lateral-torsional buckling analysis of cantilever beam with tip lateral elastic brace under uniform and concentrated load. Int. J. Steel. Struct. 2016, 16, 1161-1173. [CrossRef]

24. Deng, S.L. Research on Overall Stability Behavior of Concrete-Filled Rectangular Tubular Flange I-Shaped Beam with Elastic Bracing. Master's Thesis, Northeast Petroleum University, Daqing, China, 2018.

25. Tong, G.S. Out-Plane Stability of Steel Structures, 1st ed.; China Architecture \& Building Press: Beijing, China, 2006.

26. Chen, J. Stability of Steel Theory and Design, 6th ed.; Beijing Science Press: Beijing, China, 2014.

27. Achref, H.; Foudil, M.; Cherif, B. Higher buckling and lateral buckling strength of unrestrained and braced thin-walled beams: Analytical, numerical and design approach applications. J. Constr. Steel. Res. 2019, 155, 1-19. [CrossRef]

28. Zhang, W.F.; Liu, Y.C.; Chen, K.S. Dimensionless analytical solution and new design formula for lateral-torsional buckling of I-beams under linear distributed moment via linear stability theory. Math. Probl. Eng. 2017, 2007, 4838613. [CrossRef]

29. Zhang, W.F.; Hang, Z.M.; Liu, Y.C.; Zhao, W.Y.; Yan, W.; Hua, J.K. Study on the exact solution for critical flexural torsional buckling moments of fixed beams under combined action of uniform load and concentrated load. Struct. Eng. 2021, $37,33-41$.

30. Dietrich, M.Z.; Calenzani, A.F.G.; Fakury, R.H. Analysis of rotational stiffness of steel-concrete composite beams for lateraltorsional buckling. Eng. Struct. 2019, 198, 109554. [CrossRef]

31. 1stOpt User Manual, 7D Soft High Technology Inc., China, 2006. Available online: http://www.7d-soft.com/index.htm (accessed on 4 December 2021).

32. Ma, Z.Y.; Wang, P.F.; Wu, Z.Q.; Wu, D.L.; Su, Y. A Method for Solving the Refractive Index Temperature Coefficient Empirical Formula Constants of Optical Glasses Based on 1stOpt. Acta Photon. Sin. 2017, 46, 616002.

33. Liu, Y.C.; Hang, Z.M.; Zhang, W.F. Analytical solution for lateral-torsional buckling of concrete-filled tubular flange girders with torsional bracing. Adv. Civil Eng. 2020, 2020. [CrossRef]

34. Wang, Y.M.; Shao, Y.B.; Chen, C. Prediction of flexural and shear yielding strength of short span I-girders with concrete-filled tubular flanges and corrugated web-II: Numerical simulation and theoretical analysis. Thin. Wall. Struct. 2020, 148, 106593. [CrossRef]

35. Ji, J.; Xu, Z.C.; Jiang, L.Q.; Yuan, C.Q.; Zhang, Y.F.; Zhou, L.J.; Zhang, S.L. Nonlinear Buckling Analysis of H-Type Honeycombed Composite Column with Rectangular Concrete-Filled Steel Tube Flanges. Int. J. Steel. Struct. 2018, 18, 1153-1166. [CrossRef]

36. Ji, J.; Xu, Z.C.; Jiang, L.Q.; Liu, Y.C.; Yu, D.Y.; Yang, M.M. Experimental study on compression behavior of H-shaped composite short column with rectangular CFST flanges and honeycombed steel web subjected to axial load. J. Build. Struct. 2019, 9, 63-73. 